\title{
Anti-CTLA-4/OX40 Bispecific Antibody ATOR-1015
}

National Cancer Institute

\section{Source}

National Cancer Institute. Anti-CT LA-4IOX40 Bispecific Antibody ATOR-1015. NCI

Thesaurus. Code C157494.

A bispecific antibody consisting of a cytotoxic T-lymphocyte-associated antigen 4 (CT LA-

4) inhibitory protein fused to an OX40 agonistic human immunog lobulin G1 (IgG1)

antibody, with potential immunostimulating and antineoplastic activities. Upon

administration, anti-CT LA-4/OX40 bispecific antibody AT OR-1015 simultaneously binds to

CT LA-4 and OX40, which may inhibit CT LA-4-mediated downregulation of T-cell

activation and induce proliferation of memory and effector T-lymphocytes via OX40

activation. Both CT LA-4, an inhibitory receptor and member of the immunog lobulin superfamily (IgSF), and OX40, a cell surface glycoprotein and member of the tumor necrosis factor receptor superfamily (TNFRSF), are overexpressed by regulatory T-cells (Tregs) in the tumor microenvironment. AT OR-1015 may reduce the number of Tregs and promote the activation of effector T-cells, thereby enhancing the immune-mediated anti-tumor response. 